\title{
Carbonyl Formation from Isooctane Combustion in an Internal Combustion Engine
}

\author{
ROBERT F. HILL \\ Research Laborutories, General Mators Corporation, Warran, Michigan ABOgot
}

and

\section{S. S. PENNER}

Unitersity of California, San Diego, Latolla, California 92037

\begin{abstract}
Experimental measurements of reaction intermediates formed in hydrocarbon oxidation have been performed in laboratory $[1,2]$ and engine studies $[3,4]$. In particular, labeled 2-methylpentane has been used to study the formation and origin of ketones [S]. Mayer and Krause [6] conducted experiments with carbon- 4 labeled isooctane in a single cylinder engine.' In this paper we correlate carbon atoms in the fuel molecule with carbonyl compounds separated from the exhaust gas. The "tendeney" for carbon-cabon bond rupture and a "measure" of the probability of carbonyl. compound formation are derived

lewetane $5 \cdot \mathrm{C}^{14}$ and $4 \cdot \mathrm{C}^{14}$ were used [6]. The carbon she:
\end{abstract}

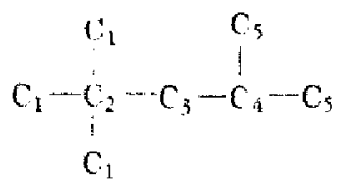

The pherone was fed direstly into the intake manitid of a single-cylinder engine. The catbonyl compounds in the oxhaust gas were extracted with

\footnotetext{
1 This report may be obtainet through a request to the

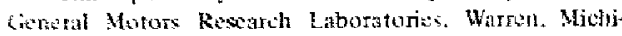
$\sin 48096$.
}

cold 2,4-dinitrophenylhydrazine. The resulting hydrazone derivatives were dissolved and separated by paper chromatngraphy, measured by specteon. photometry, and analyzed for carbour 4 comtent by liquid-scintillation spectometry. Six expeth ments were performed (three with side ald thet with $\left.4-C^{14}\right)$. Approxinately 55 liters of exlitist gas were processed in ach test. The catbuyly compounds averaged $8.4 \times 10^{-7}$ molstitite of en haust gas, which is equivalent 10 abont 37 pron.

The following carbonyl cotnpound were identit" fied: formaldehyde (group 1), acetaldehyde (goup 2), and acetone (group 3) separatod as indwidial compounds; propionaldehyde and acrolein fostrip 4) were separated together; the four taberstan compounds also separated as a group atld tonto tained the butyraldetiyde isomers and crotan. aldehyde (group 5), a mall quantity of six and seven-membered ketones was also collected gotp 6). The results are listed in Table 1.

In the following scleme of data inierpretation, we describe the observational data by a procedure that cannot answer the question of lacation of initial attack but rather shows the final offects of hydrogen abstraction, oxidation atid bonud noptjog on the resulting collection of decconpontiten fras ments.

Let $T_{i}$, equal the terdency for the catben bond $C_{j}-C_{j}$ to break during an event and fet $P_{k}$

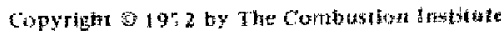

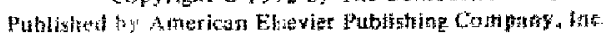


TABLE 1

Specific Activily of Carbonyt Compents Formed in a Fired lingenge |b]

\begin{tabular}{|c|c|c|c|}
\hline Group & $\begin{array}{c}\text { Cothecurrations } \\
\text { mote }\end{array}$ & 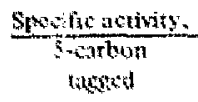 & 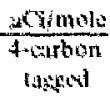 \\
\hline $\begin{array}{l}1 \\
2 \\
3 \\
4 \\
5 \\
6\end{array}$ & $\begin{array}{r}64.0 \\
5.4 \\
5.9 \\
5.6 \\
17.7 \\
1.4 \\
\end{array}$ & $\begin{array}{l}34.7^{3} \\
49.9 \\
28.8 \\
67.9 \\
73.9 \\
123.0\end{array}$ & $\begin{array}{r}267 \\
153.0 \\
48.7 \\
134.0 \\
111,10 \\
183.6\end{array}$ \\
\hline 6 & 100.0 & & \\
\hline
\end{tabular}

represent a meastre of the fact that the resulting struciures were oxidized to the arbonyl com. pounds of group " $k$. The activity of the carbonyl compounds of group "f" contining labetedcasbon atom " $i$ " is defined as $k, A_{i}={ }_{k} S_{i} M_{k}$. where $k S_{i}$ equals the specific activity of " $k$ " associated with carbon atom " $i^{+*}$ and $M_{k}$ equals the mole fration of " $k$ " formed. Setting the measured activity of the carbonyl compounds in a sperited group equal to the sum of the proders al the fendencios $\left(T_{i} j^{\prime}\right)$ and mensures $\left(R_{*}\right)$ that may lead to theit formation from is wh whe newits in the sot of aquations listed in soble 2 . The namention

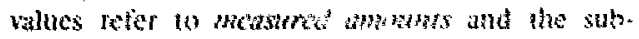
swripts "f." currespond to the group indies af Table 1.

Tretic:

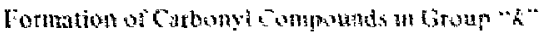
with Catbon Atoms 4 .mo 5
Reference to Table 2. shows that we have a sysiem of 12 equations in 10 unknowns $\left(R_{1}\right.$ through $R_{6}$ and $T_{12}, T_{34}, T_{34}$ and $\left.T_{45}\right)$. Solutions to this overdetermined set are listed in Table 3 ; the duplicate entries for $R_{3}$ refer to the use of the mations identified as (a) and (b), respectively, in Tabte 2 . Pormaps the variation in $R_{3}$ from 0,67 to Q83 is observed becatue asetone formation ocents not anly as the result of simple bond rupture and oxdation, as asumed in our model, but also as the resule of synthesis from smaller fragments: in any event, the observed variation is withit the experimental limits of error.

The tendency for the carbon bond $C_{2}-C_{3}$ to rupture mote readily than $\mathrm{C}_{3}-\mathrm{C}_{4}(1.22$ and 0.99 . respectively) is a result of the observed formation of large concentrations of the butyraldenydes shown by the value 17.7 for the compounds in group 5 (Table 1). More generally, the data bited in Table ; provide relative estimates for the tenderecies for hond rupture $\left(T_{23} / T_{12}, 1, T_{24} /\right.$ $\left.T_{12} \approx 0.83, T_{45} / T_{12} \approx 0.72\right)$ during isooctane combustion in an engine. This tendency for hand ravtate varies by a factor of 14 whish is in general decement with Panlitys that on bondilssocintom onteges in polyatomic molecules [7]. The measure of carbonylesinponal formation vatied by a tator of 78 with formaldehyde being the most : bundant. Relative neasures may be interpreted as indicated case of aldelyyde or ketone formbtion for the sarbonchain fragments $\left(R_{2} / R_{1} \sim 0,1 \%, R_{3} / R_{1} \sim 0.04, R_{3} / R_{1} \approx 0.10\right.$. $\left.R_{*} / R, \approx 0.7 . R_{0} / R, \approx 0.01\right)$. It we assume

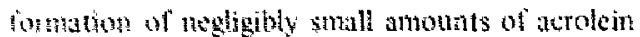
stopparat with propionaldelyde. we must con. dude that adehy fomation for the three-

Tabl. :

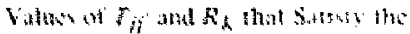

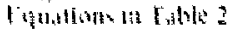

\begin{tabular}{|c|c|}
\hline $\begin{array}{l}T_{1:}=1.2 \\
T_{: 3}=1.22 \\
r_{1:}=0 \% \\
T_{1}=0,36\end{array}$ & $\begin{array}{l}R_{1}=1817 \\
R_{2}=3.15 \\
R_{*}=0.530 .67 \\
R_{*}=1.2 \\
R_{*}=4.81 \\
R_{*}=0.3\end{array}$ \\
\hline
\end{tabular}


carbon chain is about twice as likely to occur as kerone formation, a not unreasonable conclusion for the extreme conditions in engine combustion since there are two end carbon atoms that can result in aldehyde formation. while coniy the middle uarboa atom can contribute to ket one formation.

\section{References}

1. Tipper. C. F. H., Oxidation and Combustion Reviews, Vol. 1, American Elsevier. New York (1965).

2. Bafat, P., Cullis, C. F, and Pollird, R. T., The cool-flame oxidation of 3ethylpen iane, Proc. Roy. Soc. (London) A 325, 469 (1971).

3. Ninomiya, J. S.. and Golovoy. A., Effects of air-fuel ratio on composition of hydrocarbon exhaust from isooctane, ditsobutylene, toluene, and toluene-nt heptane mixture, SAE Paper 690504, 1969).

4. Fleming. R. D., and Eccleston, D. B., The effer of fuel composition. equivalence ratio, and mixture tem-

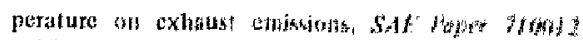
(1971).

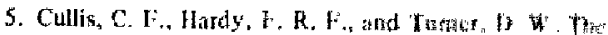

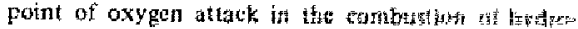

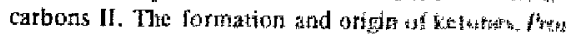
Roy. Soc. (London' A 251,265 11959 )

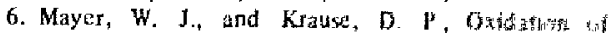

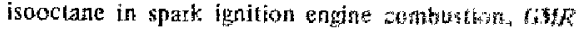

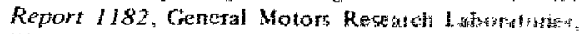
Warten, Mich. (1972)

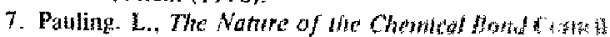
U.P., New York 11960).

TRecoived Junc 1972; rebised rersind received Algust $(97 \%)$

\section{MEETING REPORT}

\section{Fourteenth Symposium (International) on Combustion}

The Fourteenth Symposium (International) on Combustion was held August 20-24, 1972, on the campus of The Pennsylvania State University, University Park, Pa. Final registration totals included 701 registrants from 25 countcies, pius 222 wives and children. The technical program included the plenary lecture by Professor Hoyt $\mathrm{C}$. Hottel of M.I.T. on "Combustion and Energy for the Future" and 27 sessions of technical papers that incluced 12 invited reviews and $121 \mathrm{con}$ tributed papers. Four colloquia were organized for the meeting: "Elementaty Reactions in Combustion" (3" papers), "Flames in Furnaces and Combuston" (11 papers), "Poilutant Formation and Destruction in Flames" (27 papers), and "Fire and Explosion" (21 papers). Other sessions were held on Laminar Flames, Oxidation and Ignition, Oscillatory Combustion, Turbulent and Supersonic Combustion, Detonations. Propeliant Research, and Heterogeneuus Combustion. rapers were general creellent and a graat deal of lively and fruitful discussion took place at sessims thmongt. out the week. The full procedinge with bo patip. lished by the Combustion Instiute tumy 1975 Orders can be placed by writing to this Exectitura Secretary, Mrs. Helen G. Bangs, the Combestion

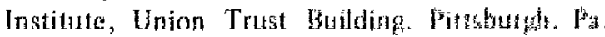
15219.

Nontechneal activities associated with the newt ing included tours of the Centrat Pontwytyon

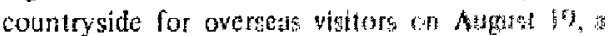

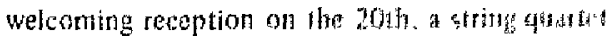
concert on the 21st, a theater party on the 27 sul, is picnic and cave trip on the $230 \mathrm{~d}$, and the lass itula Banquet on the 24th. An extensive Latives Pay. gram includel a variety of expoditione. special programs, tcas, and luncheons.

At the Banquet, Combustion lonstituse award were presented as rollows:

The Sir Alfred Edgertan Metai "log tistip" guished continuirg and encouraging contritutiots to the field of combustion ${ }^{*}$ is Dr. Whand 